\title{
A política econômica brasileira diante da Covid-19
}

\author{
The Brazilian Political Economy against Covid-19
}

Lauro Mattei ${ }^{1}$

\begin{abstract}
Resumo:
Neste artigo são discutidas as bases da política econômica destinada ao combate da Covid-19. De um modo geral, notou-se que a ideologia econômica neoliberal determinou os rumos das ações econômicas do governo atual. Após analisar um conjunto de medidas de apoio aos empresários, trabalhadores e segmentos sociais vulneráveis, concluiu-se que a política econômica fracassou e, consequentemente, estimulou o aumento do número de empresas que encerraram suas atividades, bem como contribuiu para elevar fortemente o nível de desemprego que, registre-se, já era elevado anteriormente ao início da pandemia.
\end{abstract}

Palavras-chave: Brasil. Covid-19. Política Econômica.

\begin{abstract}
:
In this article are discussed the political economy rules against the Covid-19. In the general terms, we are noting that neoliberal economic ideology determined the course of the federal governmental economic actions. After to analyse the main measures to support both entrepreneurs, workers, and social segments in a vulnerable condition, the paper emphasized the failure of the main political economy actions, and highlighted that this situation help to increase the number of entrepreneur's failure and also to increase the unemployment level, which was very high before the pandemic scenario.
\end{abstract}

Keywords: Brazil. Covid-19. Political Economy.

\section{Introdução}

Em dezembro de 2019 o mundo foi apresentado ao novo coronavírus, tendo como epicentro a cidade de Wuhan, província de Hubei, China. Rapidamente a doença (Covid-19) provocada por esse vírus se espalhou por outros locais da China e, posteriormente, pelo mundo, causando uma das maiores crises sanitárias da história da humanidade. Por isso, em 11.03.2020 a Organização Mundial da Saúde (OMS) decretou a doença Covid-19 como pandemia, em função do aumento expressivo dos casos e da disseminação da mesma para quase todos os países do mundo. A definição de pandemia é utilizada

\footnotetext{
${ }^{1}$ Professor Titular dos cursos de Graduação em Economia e de Pós-Graduação em Administração, ambos da UFSC. Coordenador Geral do NECAT-UFSC e Pesquisador do OPPA/CPDA/UFRRJ. Email: 1.mattei@ufsc.br. https://orcid.org/0000-0002-1270-8052.
} 
quando uma doença infecciosa se espalha rapidamente e afeta um grande número de pessoas em todo globo terrestre. Essa decretação de pandemia, na verdade, serve para alertar os chefes de Estado sobre a gravidade do problema e a necessidade de se adotar medidas de saúde pública para preservar a vida das populações. Assim sendo, e diante da inexistência de um medicamento específico para seu combate, a OMS sugeriu o isolamento e o distanciamento social como forma de se impedir o contágio e, desta maneira, evitar a sobrecarga dos sistemas públicos de saúde num período de tempo muito breve.

No Brasil o primeiro caso foi confirmado oficialmente no dia 26.02.2020. A partir dessa data até meados de março, a maioria dos casos conhecidos ocorreram por contaminação externa, ou seja, brasileiros foram infectados por meio de contatos com pessoas de outros países onde a doença já estava circulando. Todavia, após o surgimento dos primeiros casos de transmissão comunitária ainda na primeira quinzena de março de 2020, ou seja, quando não era mais possível identificar o agente transmissor da doença, a epidemia passou a ganhar destaque, especialmente na área de saúde do governo federal. Foi então que o Ministério da Saúde, seguindo as recomendações da OMS, adotou a medida do isolamento e distanciamento social como estratégia de ação para evitar a explosão da contaminação da população, uma vez que até o momento ainda não existe uma vacina eficaz para controlar a epidemia. Obviamente que estava claro a todos que essa crise de saúde era global e que provocaria efeitos também nas esferas econômica e social em praticamente todos os países.

Todavia, tal temática fez com que o Brasil fosse um dos poucos países em que esse assunto se transformasse em um caso político de grandes proporções, inclusive provocando a demissão do ministro da saúde que estava coordenando as ações de combate à Covid-19 no país. Na verdade, se instaurou no país um falso debate entre saúde $\mathrm{x}$ economia, dicotomia essa fortemente estimulada pelo próprio Presidente da República e pelo Ministro da Economia, os quais reiteradamente questionavam o uso do isolamento como estratégia de combate aos problemas causados pelo novo coronavírus. No entender desses senhores, o uso demasiado dessa medida poderia desorganizar a economia, chegando-se ao ponto de se afirmar que os custos da recessão econômica poderiam ser mais prejudiciais do que a própria pandemia.

É exatamente sobre as questões econômicas que esse ensaio irá se debruçar com o intuito de elucidar alguns elementos centrais envolvidos nas decisões da política econômica adotada durante a pandemia, destacando suas principais consequências. Portanto, além dessa breve introdução, o artigo é composto por mais três seções. Na primeira delas faremos uma breve síntese da política econômica e das medidas adotadas para, na seção seguinte, debater alguns impactos sobre as principais atividades econômicas. A terceira seção apresentará algumas considerações gerais, destacando-se a ineficácia da política econômica para mitigar as externalidades negativas provocadas pela pandemia. 


\section{A política econômica brasileira durante a pandemia}

O século XXI vem apresentando crises econômicas sistêmicas. Na primeira década, o mundo foi fortemente abalado pela crise financeira de 2008-2009, cujo epicentro ocorreu na esfera financeira, porém com contágio sobre a economia real em todas as partes do globo terrestre. Seus efeitos se fizeram sentir por vários anos, sendo que diversos países até hoje não conseguiram retornar à situação pré-crise. Já a terceira década iniciou com uma nova crise econômica totalmente diferente das anteriores, uma vez que agora são as consequências da pandemia da Covid-19 - fenômeno sanitário que já atingiu mais de 200 países em todo o mundo - que irão prevalecer. É importante registrar que esta nova crise é bem distinta das crises anteriores, uma vez que aquelas derivaram do próprio funcionamento das estruturas econômicas. Agora as sociedades estão enfrentando uma crise sanitária de proporção global que, além ceifar vidas em todos os lugares, tem causado impactos negativos expressivos na economia de todos os países. Com isso, hoje já se sabe que os efeitos econômicos da Covid-19 não serão de curta duração - 3 a 4 meses como vinha sendo dito pelo Ministro da Economia do Brasil - e que seus impactos poderão destruir a estrutura econômica de um determinado país, caso seus governantes não adotem medidas efetivas para enfrentar a nova realidade.

Neste sentido, diversas instituições internacionais (Banco Mundial, Fundo Monetário Internacional e OCDE) entendem que neste momento os governos nacionais devem deixar de lado o discurso da austeridade fiscal e adotar medidas urgentes em duas direções: por um lado, conter a pandemia com o intuito de salvar vidas e, por outro, buscar estimular a economia para evitar o caos econômico e social. Sem dúvida, essa nova fase está mostrando claramente ao mundo que o ideário econômico neoliberal que pautou as intervenções econômicas nas últimas cinco décadas está sendo fortemente questionado. Ao mesmo tempo emerge novamente a importância do Estado enquanto agente decisivo para implementar políticas que sejam capazes de reaquecer as atividades econômicas.

\section{A economia brasileira antes da pandemia}

A economia brasileira já vinha capengando desde 2015 segundo alguns indicadores básicos, como é o caso do PIB que, em média, apresentou taxa de crescimento negativa da ordem de $0,90 \%$ ao ano entre 2015 e 2019. Nesse período foram realizadas diversas reformas tratadas como salvadoras da pátria (limitação do teto de gastos públicos, reforma trabalhista e reforma da previdência), mas que pouco contribuíram, uma vez que desde então o país convive com taxas de desemprego elevadas e com as piores taxas de investimento das últimas duas décadas.

No ano de 2019 os dados do PIB revelaram que a economia brasileira já continuava com problemas antes mesmo de ser afetada pelo novo coronavírus. Isto porque, além do crescimento ter se reduzido em relação ao ano anterior, o mesmo se situava em semelhante patamar de 2013. Por um lado, o 
consumo do governo foi negativo, as exportações de bens e serviços caíram $2,5 \%$, enquanto a taxa de investimento continuava num patamar bastante baixo (15\% do PIB), comparativamente ao seu ápice verificado nos anos anteriores à crise (21\% do PIB). Por outro, o pequeno crescimento divulgado estava fortemente atrelado à expansão do consumo das famílias, indicador importante, porém com sérias limitações para se garantir taxas sustentáveis de crescimento, especialmente em situações em que perdurarem taxas de desempregos elevadas devido à retração das atividades econômicas. Mesmo diante desses fatos, o Ministro da Economia continuava afirmando nos meios de comunicação que o país estava em pleno voo e começando a decolar quando foi atingido por essa onda que veio de fora. Para ele, enquanto a economia mundial estava em descenso, o Brasil entrava em rota de crescimento de $2 \%$ para esse ano.

Uma economia nas condições acima reportadas e afetada diretamente pela crise decorrente do novo coronavírus certamente teria enormes desafios pela frente. Diante disso, o governo federal precisava atuar rapidamente em três frentes essenciais: garantir a solvência das empresas - sobretudo aportando capital de giro - para que elas continuassem funcionando; garantir a manutenção dos níveis de emprego e de salários dos trabalhadores; e atender aos segmentos mais vulneráveis da população que, além de excluídos economicamente, estariam mais expostos à própria epidemia. Registre-se que são estratégias bastante semelhantes a essas que foram adotadas na maioria dos países do mundo. Infelizmente, não parece ter sido essa a escolha da área econômica do governo brasileiro, uma vez que a maioria das medidas anunciadas em conta-gotas, além de ser tímidas e pouco eficientes para enfrentar as três dimensões acima expostas, demoraram demasiadamente para serem implementadas, o que pode ter contribuído para inibir o funcionamento das atividades econômicas e agravar os problemas sociais do país.

De um modo geral, o que ficou nítido nesses quatro meses de pandemia é que o governo não tinha (e ainda não tem) um plano de ações organizado e articulado para amenizar os efeitos da pandemia nas atividades econômicas. O que se viu foram anúncios espalhafatosos e a conta-gotas de montantes de recursos, porém sempre com poucos efeitos práticos. Chamou atenção, ainda, que nesse período as ações da equipe econômica continuaram pautadas pelas ideias das reformas estruturais, pela retomada de programas de privatizações e pela cantilena da não expansão dos gastos fiscais, opções que vão exatamente na contramão de tudo o que vem sendo feito na maioria dos países também afetados pela Covid-19.

Além disso, outros fatos complementares destacam-se: o Ministro da Economia acreditava que a crise seria apenas uma turbulência passageira, pois segundo ele a economia do país era resiliente e estava com os fundamentos fiscais e com as reformas estruturantes em andamento; que foram divulgadas muitas informações sobre o volume global de recursos disponibilizado para combater a pandemia, mas que na prática esses recursos não chegavam aos destinatários; que era evidente o descompasso entre os anúncios das medidas e a implementação efetiva das mesmas, fato que estava contribuindo para agravar ainda mais 
as já precárias condições de vida de importantes parcelas da população; e que todas as ações da equipe econômica rejeitavam uma atuação mais robusta do Estado, em termos da expansão do gasto público.

\section{O credo neoliberal prevaleceu nas ações de política econômica}

Nesse cenário de pandemia, os dogmáticos economistas neoliberais da atual equipe do governo federal continuavam defendendo a cantilena de que o Estado estava quebrado e que não havia recursos para qualquer ação mais robusta nesse momento de crise. $\mathrm{Na}$ verdade, essa retórica neoliberal já vinha sendo adotada desde o impeachment de 2016 quando se passou a apostar que a austeridade fiscal e as reformas estruturais estabilizariam a economia, via expansão das atividades produtivas em todo o país. No entanto o que se verificou com a efetivação de um conjunto de reformas, foi uma economia cada vez mais estagnada. E em plena crise provocada pelo novo coronavírus, novamente se colocou como prioridade a continuidade dessas reformas estruturais, com destaque para duas delas: a administrativa e a tributária. Mesmo que nesses últimos quatro anos as reformas realizadas não conseguiram reativar o crescimento econômico em níveis sustentáveis, a narrativa das reformas continuou sendo o assunto predileto enquanto estratégia do Ministro da Economia para fazer frente aos impactos da Covid-19.

Foi neste contexto que se criou no âmbito do ministério da economia um grupo de trabalho responsável pelo gerenciamento da crise. Tal grupo apresentou na segunda semana de março as primeiras medidas de política econômica para fazer frente ao novo cenário, destacando-se que o foco das intervenções do governo continuava nas reformas, além do desejo de privatizar o sistema Eletrobrás. $\mathrm{Na}$ semana seguinte ao anúncio das primeiras medidas, o Ministro da Economia voltou a afirmar que a melhor resposta para conter a crise atual é aprovar as reformas no Congresso Nacional porque essas reformas, segundo ele, são a base para gerar crescimento, emprego e renda. E justificou esse posicionamento afirmando que com as reformas o país aumentaria sua resistência para atravessar a turbulência que vinha de fora.

Nas semanas seguintes, percebeu-se que a ideia das reformas estruturais estava associada à temática do emprego e dos salários. Com isso, a agenda política da equipe econômica passou a ser definida a partir de pautas apresentadas pelas representações de setores empresariais. Neste caso, destacam-se as Medidas Provisórias (MP) 927 que, além de desconfigurar a CLT, inicialmente permitia a suspensão dos contratos de trabalho por quatro meses sem pagamento dos salários. Parte da MP 927 foi apresentada novamente no início de abril como MP 936, onde foi delineada a política em vigor no momento, com destaque para a suspensão dos contratos de trabalho por até quatro meses, com parte da remuneração sendo paga pelo programa seguro-desemprego, e com redução de jornada de trabalho e salários de forma proporcional. 
É importante registrar que durante todo o mês de março o ministro da economia se mostrou fiel ao presidente em sua desiderata pelo fim do isolamento social decretado pelos governos estaduais, ao mesmo tempo em que reafirmava a cartilha econômica neoliberal. Assim, em vídeo gravado em sua residência ao final do mês de março afirmou que a Covid-19 não deveria desorganizar a economia, mesmo que o governo precisasse cuidar da saúde. Para tanto, repetiu a mesma argumentação de que se todo mundo ficasse em casa a economia iria entrar em colapso, levantando, inclusive, a hipótese do desabastecimento para reafirmar a necessidade de se implementar medidas de isolamento social menos duras.

O ápice desse comportamento ocorreu no último sábado de março quando o ministro da economia fez uma conferência eletrônica com especuladores do mercado financeiro liderados pela XP Investimentos. Em sua exposição o ministro defendeu que se deveria implementar medidas menos duras de isolamento social porque era necessário impedir uma crise de desabastecimento e minimizar os impactos da pandemia na produção econômica. Após voltar a sua tese das duas ondas - a primeira gera crise na saúde e a segunda provoca recessão econômica - finalizou sua intervenção afirmando que depois da crise e da pandemia, com juros baixos e com câmbio elevado, seriam levadas adiante as privatizações, além do que as reformas continuariam sendo o foco da equipe econômica.

\section{Algumas medidas econômicas e seus resultados práticos}

Entre os meses de março e maio o governo divulgou diversas medidas, as quais nem sempre obedeceram a uma ordem lógica de ação diante dos problemas que surgiram na economia e que afetavam, tanto o setor empresarial como a classe trabalhadora, além dos segmentos sociais vulneráveis e invisíveis, especialmente os desempregados e os trabalhadores informais que, em grande parte, vivem dos famosos "bicos".

Todos aqueles que tiveram a oportunidade de acompanhar os anúncios das medidas perceberam facilmente que o Ministro da Economia gostava de falar em grandes números, chegando ao ponto de afirmar nas últimas falas que já tinha investido mais de $\mathrm{R} \$ 800$ bilhões para combater os efeitos negativos provocados pelo novo coronavírus no sistema econômico e que o governo não tinha mais dinheiro para continuar pagando o auxílio emergencial nos valores definidos em lei. Todavia, nem sempre essas afirmações correspondiam aos fatos, como foi o caso do anúncio do primeiro pacote de ações, quando se espalhou que o governo estaria investindo R $\$ 148$ bilhões. Análises posteriores sobre as ações divulgadas identificaram que praticamente todo o montante anunciado dizia respeito a antecipações de recursos já previstos no orçamento de 2020, ou seja, não havia nenhuma injeção de dinheiro novo em praticamente tudo o que foi divulgado. Registre-se que essa prática foi se repetindo em diversos anúncios subsequentes. 
Ao longo de meses foram anunciadas diversas medidas de apoio ao setor empresarial, sobretudo às micro, pequenas e médias empresa, tanto por parte da equipe do Ministério da Economia como por parte do BNDES e Banco Central. Ao longo dos meses foi prometido a esses setores um montante da ordem de R\$ 60 bilhões. Todavia, hoje está claro que esses anúncios tiveram pouca efetividade, uma vez que estudos recentes, bem como declarações de representantes de vários setores empresariais, evidenciaram o fracasso de praticamente todas essas medidas, fato aliás que foi reconhecido publicamente por gestores do próprio ministério.

Essa falta de apoio a esses setores foi identificada recentemente pela pesquisa SEBRAE/FGV (2020), uma vez que do montante de crédito destinado às empresas, apenas 1,45\% foi destinado para os Microempreendedores Individuais (MEI); 7,3\% para as microempresas; e 24,6\% para pequenas empresas. O estudo percebeu que a reduzida participação desses segmentos de empresas no volume total de crédito está atrelada ao baixo índice de concessão de crédito aos MEI e MPEs, uma vez que esses segmentos possuem maiores dificuldades para aprovar cadastros de concessão de crédito, dadas as exigências de garantias por parte do sistema financeiro. Esse aspecto foi traduzido em números pela pesquisa, ou seja, do total de micro e pequenas empresas que buscaram crédito em bancos apenas 15,9\% tiveram êxito. Já no caso dos MEI a situação é ainda mais grave, uma vez apenas 10,8\% dos solicitantes conseguiram algum apoio do sistema bancário.

Já pesquisa recente do IBGE (2020a) observou que das 2,7 milhões de empresas, 70\% delas sofreram impactos negativos da Covid-19. Somente na primeira quinzena de junho de 2020 aproximadamente 1,3 milhões de empresas estavam com atividades encerradas temporariamente ou definitivamente, especialmente nos ramos de serviços, comércio, indústria de transformação e construção civil. O estudo concluiu que a Covid-19 afetou mais fortemente os segmentos empresariais com contatos pessoais diretos e aqueles mais intensivos em trabalho que atuam prestando serviços às pessoas e famílias, como bares, restaurantes, hotéis, pousadas, academias, cabelereiros, manicures, etc.

Neste cenário é de se esperar que o nível de endividamento desses setores empresariais irá aumentar; que o risco de inadimplência se tornou real; que os compromissos em atraso vão aumentar; e que o acesso ao crédito para manutenção de negócios e empregos irá se tornar mais difícil. A consequência não poderia ser mais sombria: demissão dos funcionários e encerramento das atividades.

\section{Açôes específicas relativas ao emprego e salário}

As MPs 927 e 936, que autorizavam a suspensão de contratos de trabalho e a redução da jornada de trabalho com correspondente redução de salários, preconizavam que o governo iria preservar, com tais medidas, aproximadamente 25 milhões de empregos. Informações divulgadas eletronicamente pelo Ministério da Economia no início de julho revelaram que o programa atendeu cerca de 9,1 milhões de trabalhadores, sendo que a maioria teve os contratos de trabalho suspensos. 
Por isso, a PNAD Continua (IBGE, 2020b) relativa ao trimestre março-maio, que registra integralmente os efeitos da pandemia, apontou uma elevação da taxa de desemprego para 12,9\%, o que corresponde a aproximadamente 12,7 milhões de pessoas. A esse contingente temos de somar os desalentados e os informais, o que revela a gravidade da situação no mercado de trabalho no país, que tenderá a piorar após cessar os efeitos das MPs anteriormente mencionadas.

\section{Ações destinadas aos segmentos sociais vulneráveis}

O Congresso Nacional aprovou o Programa de Auxílio Emergencial destinado aos trabalhadores informais e microempreendedores individuais para fazer frente ao problema econômico causado pelo novo coronavírus. A partir daí se sobressaíram diversos problemas na implementação dessa política. O primeiro deles foi o longo atraso, por parte da equipe econômica do governo federal, na implementação do programa, pois a cada momento se inventava uma nova trava para claramente retardar o processo de expansão do gasto governamental que tal ação exigia. O segundo aspecto diz respeito à letargia das equipes governamentais envolvidas na implementação dessa nova política social. O terceiro aspecto é a burocratização excessiva para os recursos efetivamente chegarem aos mais necessitados.

Finalmente, um último aspecto que ficou explícito na demora do governo de mais de um mês para atender aos segmentos sociais mais vulneráveis é de caráter puramente ideológico. Depois do projeto ser aprovado no Congresso Nacional o presidente levou três dias para assiná-lo e, na sequência, o ministro da economia inventou a história de que seria preciso mudar a constituição para proceder ao pagamento. O corpo mole da área econômica neste caso encontra explicação na fala do presidente do Banco do Brasil. Em 02.04.20 esse senhor declarou ao jornal Estadão de São Paulo que esmolas só atenuam o problema, mas não o resolvem e que a crise requeria ações públicas, porém era preciso ter cuidado para não se montar um grande Estado assistencialista, porque depois ficaria mais difícil desmontá-lo. É essa ideologia anti Estado que domina o núcleo econômico do governo e que também se explicita em diversas outras esferas, como no caso dos salários dos servidores públicos.

\section{A visão crítica sobre a política econômica atual}

Ao longo do período da crise decorrente da Covid-19, economistas de distintas correntes do pensamento econômico se manifestaram em relação às medidas adotadas, bem como em relação à leitura do cenário econômico feita pelo Ministro da Economia. A seguir destacaremos algumas dessas interpretações, as quais guardam proximidade com as nossas interpretações.

Em artigo intitulado "A enrolação de Paulo Guedes: o Rolando Lero da Economia", o professor José Oreiro (UNB) afirmou que enquanto o Ministro Guedes fica brincando de enrolar a sociedade brasileira com medidas cosméticas, os países desenvolvidos montam programas colossais de aumento do gasto público, entre os quais destacam-se o programa francês de cancelamento das contas de aluguel, luz e água (as quais deverão ser pagas pelo Estado) ou ainda a proposta do Senador Mitt Rommey do Partido Republicano dos EUA de dar US\$ 1000 para cada americano adulto. O enorme contraste entre a 
embromação de Paulo Guedes e as medidas radicais que estão sendo postas em prática pelos países desenvolvidos mostra o grau de despreparo e amadorismo do Ministro da Economia (OREIRO, 2020).

Pérsio Arida, por sua vez, em artigo intitulado "Despreparado para a guerra", afirmou que a resposta do Governo tem sido tímida, desorganizada e a reboque dos fatos. A garantia de que não faltará dinheiro para saúde foi importante, mas muitas medidas anunciadas com pompa e circunstância não saíram do papel. E muito mais deve ser feito, tanto para pessoas físicas quanto para empresas, para reduzir ao mínimo o impacto da crise (ARIDA, 2020).

Já Armínio Fraga, em entrevista ao jornal O Globo, afirmou que pelo lado da economia a ação ganha contornos de urgência, em função do colapso súbito das receitas das pequenas, médias e grandes empresas, dependendo do setor esse colapso chega a 100\%. Numa recessão a receita cai a uma taxa média de 10\%, gerando uma onda enorme de desemprego. Por isso é importante agir rapidamente. E isso não está acontecendo (FRAGA, 2020).

O enfrentamento da Covid-19 exige, segundo Bresser-Pereira, respostas mais fortes do governo daquelas que foram apresentadas, sendo necessário aumentar os investimentos, por parte do governo, em infraestrutura sem depender apenas de concessões. Essa ação certamente levaria ao aumento da demanda e, consequentemente, promoveria a retomada do crescimento do Produto Interno Bruto (PIB). Isto porque, segundo esse economista, a crise do novo coronavírus veio se somar a uma crise financeira crônica que já se estende desde 2015. São essas duas crises que vêm se agravando no governo Bolsonaro que não conseguiu o mínimo de confiança por parte da sociedade. Portanto, fica claro que o governo é muito fraco e está sem capacidade de realizar as ações necessárias (PINTO, 2020).

Para Mônica de Bolle, professora da Johns Hopkins University (Washington), o Ministro da Economia está completamente despreparado para enfrentar a crise. A sua incapacidade para se desprender dos dogmas ideológicos é completamente inapropriada para esse momento. Por isso, o governo não fez quase nada e é uma inércia absoluta. Para a professora, hoje dane-se o Estado Mínimo, você precisa gastar e é preferível errar pelo lado do excesso do que permanecer na inércia (MENDONÇA, 2020).

\section{Considerações finais}

Analisando o conjunto de ações anunciadas pela área econômica do governo ao longo dos últimos quatro meses para fazer frente ao cenário de crise causado pelo novo coronavírus, sobressaem diversos aspectos negativos de tais ações diante da realidade do país. Em primeiro lugar, observou-se que o governo não tinha (e ainda não tem) um plano de ações organizado e articulado para amenizar os efeitos negativos da pandemia sobre as atividades econômicas. O que se viu foram muito anúncios espalhafatosos e a conta-gotas sobre volume de recursos, porém com poucos efeitos práticos, uma vez que os encaminhamentos para que de fato esses montantes anunciados cheguem aos agentes econômicos que mais necessitam (empresários e trabalhadores) normalmente são lentos ou até mesmo sequer ocorrem. No geral, o que se viu foi a adoção de medidas pontuais ad hoc e ao sabor de pressões setoriais, como foi o 
caso explícito da construção da política de emprego e salário que resultou nas MPs 927 e 936. Medidas as quais tiveram seus conteúdos assentadas nas reivindicações da Confederação Nacional da Indústria (CNI) e nas opiniões de especuladores financeiros representados pela XP Investimentos.

Um segundo aspecto diz respeito ao timing das ações anunciadas, uma vez que se fez uma leitura equivocada da pandemia, classificando-a como uma turbulência passageira com duração de três ou quatro meses. A partir desse equívoco foram desenhadas ações de política econômica para combater a crise com periodicidade para dois ou três meses, como foram os casos das duas MPs relacionadas ao mercado de trabalho. Esse comportamento levou diversos analistas a afirmar que o ministro da economia do Brasil tinha uma leitura equivocada sobre o contexto econômico global decorrente da crise provocada pelo novo coronavírus e, consequentemente, pouca noção sobre a gravidade do problema para o país.

Nesta direção, o atual secretário de política econômica do ministério, em conferência com a empresas de consultoria, afirmou que nenhuma medida da equipe econômica iria além de 2020 e que todas as decisões seriam tomadas com calma, avaliando-se a temperatura de cada semana, enquanto que no mesmo diapasão o secretário do Tesouro Nacional declarou que a pandemia não mudou o pensamento da casa, uma vez que a política fiscal expansionista neste ano não é a típica política Keynesiana de expansão do gasto e investimento público. É apenas transferência de renda num período mais crítico da crise e somente isso.

Um terceiro ponto negativo que se observou foi a letargia das equipes do ministério na implantação das medidas anunciadas. Esse procedimento, na prática, contribuiu para agravar ainda mais uma situação econômica e social que já era precária, considerando-se que entre 2015 e 2017 o país enfrentou uma grave crise econômica, cujos rastros mais visíveis foram a expansão elevada do desemprego e de desestruturação do mercado de trabalho, aliada à expansão da pobreza em percentuais elevados. Aqui caberia um arsenal de casos que mostram com clareza essa letargia, mas destacamos apenas o Programa de Auxílio Emergencial destinado aos trabalhadores informais e aos microempreendedores individuais aprovado pelo Congresso Nacional. Diante de duras críticas destinadas à equipe econômica e ao próprio governo por parte de integrantes do poder legislativo, do poder judiciário e também de representações da sociedade civil, e de filas intermináveis em todo o país, o governo saiu da zona de conforto e, com muitos dias de atraso, fez os primeiros pagamentos do referido auxílio.

Por fim, mas não menos importante, foi a reafirmação contínua das ideias dogmáticas neoliberais do "Estado mínimo", rejeitando ações mais robustas do Estado, à luz daquilo que estava sendo feito na maioria dos países do mundo também afetados pelo novo coronavírus. Nesses países, verificou-se que é exatamente a máquina do Estado que tem se transformado no ente que define e lidera as ações e estratégias, tanto de combate à doença como de proteção aos sistemas econômicos. De fato, o cenário econômico do país está chamando esses dogmáticos neoliberais a um banho de realidade, uma vez que 
não cabe na crise atual o surrado argumento de que o Estado está quebrado e que não há recursos para qualquer ação mais robusta.

Mesmo assim, na agenda de prioridades do atual ministro ganharam espaço em plena crise as reformas administrativa e tributária e a reativação do programa de privatizações. A nosso ver, decorrem dessa concepção os limites das ações econômicas atuais e a própria letargia na implementação das mesmas, ficando claro em diversos momentos que a preocupação do ministro era acalmar o mercado financeiro, conforme atestam suas diversas conferências eletrônicas com especuladores desse mercado realizadas nos meses de março, abril e maio, sendo que em uma delas falou-se claramente que haveria um desvio transitório da rota, mas que em breve se voltaria à estratégia de sempre, ou seja, a agenda das "reformas estruturais".

Em síntese, destacamos esses diversos aspectos para demonstrar que a política econômica neoliberal do governo atual, além de caminhar na contramão da maioria dos países que se encontram em situação semelhante ao Brasil por também terem sido afetados pelo novo coronavírus, já está se transformando em um rotundo fracasso. Neste sentido, é importante deixar claro que, diferentemente do que foi externado na data de 07.05.20 pelo Ministro da Economia na marcha rumo ao STF, o colapso econômico por ele mencionado deriva muito mais da inoperância das medidas econômicas assentadas no credo neoliberal do que dos mecanismos de distanciamento social adotados pelos estados e municípios para conter a pandemia.

\section{Referências}

ARIDA, P. Despreparado para a Guerra. Jornal Folha de São Paulo, Página A3, 27.03.2020.

FRAGA, A. A economia pode sofrer um segundo Baque. Jornal O Globo, entrevista em 27.03.2020.

IBGE, Instituto Brasileiro de Geografia e Estatística. Pesquisa Pulsa Empresa: impactos da COVID-19 nas empresas. Rio de Janeiro (RJ): IBGE, 2020a.

IBGE, Instituto Brasileiro de Geografia e Estatística. Pesquisa PNAD Continua (trimestre móvel março-maio). Rio de Janeiro (RJ): IBGE, 2020b.

MENDONÇA, Eloísa. Monica De Bolle: "Hoje, dane-se o Estado mínimo, é preciso gastar e errar pelo lado do excesso. Entrevistada: Monica De Bolle. Jornal E1 País, 01 abr.2020. Disponível em: https://brasil.elpais.com/economia/2020-04-01/monica-de-bolle-hoje-dane-se-o-estadominimo-e-preciso-gastar-e-errar-pelo-lado-do-excesso.html

OREIRO, J. L.C. A enrolação de Paulo Guedes: o Rolando Lero da Economia. Artigo publicado no Blog do autor. https://jlcoreiro.wordpress.com. Acessado em 15.07.2020

PINTO, Paulo Silva. Bresser-Pereira defende participação maior do Estado na economia contra covid-19. Entrevistado: Luis Carlos Bresser-Pereira. Jornal Eletrônico Poder 360. Brasília, D.F., 16 mar.2020. 
SEBRAE, Serviço Brasileiro de Apoio às Micro e Pequenas Empresas; FGV, Fundação Getúlio Vargas. Crédito no Brasil para as micro e pequenas empresas em tempo de COVID-19. Brasilia (DF): SEBRAE; FGV, 2020. Disponível em:

https://fgvprojetos.fgv.br/sites/fgvprojetos.fgv.br/files/cra0dito no brasil para mpes em tempo de covid19 formatacaosite.pdf

Recebido em: junbo de 2020

Aprovado em: julbo de 2020 